\title{
Type 2 diabetes mellitus and inflammation: Prospects for biomarkers of risk and nutritional intervention
}

This article was published in the following Dove Press journal:

Diabetes, Metabolic Syndrome and Obesity:Targets and Therapy 25 May 2010

Number of times this article has been viewed

\author{
Alaa Badawi' \\ Amira Klip ${ }^{2}$ \\ Pierre Haddad ${ }^{3}$ \\ David EC Cole ${ }^{4}$ \\ Bibiana Garcia Bailo1,5 \\ Ahmed El-Sohemy ${ }^{5}$ \\ Mohamed Karmali' \\ 'Office for Biotechnology, Genomics \\ and Population Health, Public Health \\ Agency of Canada, Toronto, ON, \\ Canada; ${ }^{2}$ Cell Biology Program, The \\ Hospital for Sick Children, Toronto, \\ ON, Canada; ${ }^{3}$ Natural Health Products \\ and Metabolic Diseases Laboratory, \\ Department of Pharmacology \\ and Montreal Diabetes Research \\ Centre, Montreal, QC, Canada; \\ ${ }^{4}$ Department of Laboratory Medicine \\ and Pathobiology, ${ }^{5}$ Department of \\ Nutritional Sciences, University \\ of Toronto, Toronto, ON, Canada
}

\begin{abstract}
Obesity is a major risk factor for type 2 diabetes mellitus (T2DM), which is a significant health problem worldwide. Active disease is associated with low-grade chronic inflammation resulting in part from the activation of the innate immune system. In obesity, this activation leads to the release of pro-inflammatory cytokines such as tumor necrosis factor- $\alpha$, interleukin- $1 \beta$ and interleukin- 6 that block major anabolic cascades downstream of insulin signaling and thus disrupt insulin homeostasis and action. Cytokines also trigger the production of acute-phase reactants such as C-reactive protein, plasminogen activator inhibitor-1, serum amyloid-A, and haptoglobin. The elevated synthesis of pro-inflammatory cytokines and acute-phase proteins (inflammatory network) characterizes the early (or pre-clinical) stages of T2DM and exhibits a graded increase with the disease progression. Current evidence suggests that understanding inflammatory networks can point to new biomarkers that may permit capturing the interaction between genetic and environmental risk factors in the pathogenesis of T2DM. Such biomarkers have a significant public health potential in the prediction of disease occurrence beyond risk factors presently monitored, such as family history, lifestyle assessment and standard clinical chemistry profiles. Furthermore, inflammatory markers may assist in the evaluation of novel strategies for prevention, particularly in relation to micronutrients. This review discusses the current knowledge linking T2DM risk to inflammatory signaling pathways interacting with the innate immunity system and the prospect of inflammatory markers serving as molecular targets for prevention and/or biomarkers for early risk prediction of T2DM. The potential of micronutrients replenishment to improve insulin action by attenuating inflammation is also evaluated in the context of the public health relevance of this approach.
\end{abstract}

Keywords: inflammation, biomarkers, prevention, type 2 diabetes

\section{Introduction}

Type 2 diabetes mellitus (T2DM) represents a significant global health problem. It is estimated that six people die every minute from the disease worldwide, a figure that will soon make T2DM one of the world's most prevalent causes of preventable mortality. ${ }^{1}$ The incidence of disease increases with age, obesity, physical inactivity, unhealthy diet, and ethnicity (Hispanics, Africans, and Aboriginals) and the rates are increasing among children. ${ }^{2,3}$ T2DM is caused by impaired glucose tolerance (IGT) as a result of insulin resistance and consequential islet $\beta$-cell exhaustion, with ensuing insulin deficiency impacting skeletal muscle, liver and adipose tissues. ${ }^{4}$ In individuals with IGT, numerous genetic, host-related, and environmental factors contribute to the progression of insulin resistance to T2DM..$^{5-9}$ Obesity, however, is a major cause of insulin resistance ${ }^{7}$ and can be complicated by metabolic dysregulation including 
hypertension and dyslipidemia (known collectively as the metabolic syndrome) which is a precursor of T2DM. The dyslipidemia involves high levels of triacylglycerides and circulating fatty acids originating from the diet or accelerated lipolysis in adipocytes. Direct exposure of muscle cells to these fatty acids impairs insulin-mediated glucose uptake and, therefore, may contribute to insulin resistance..$^{10,11}$

Within the last decade, a hypothesis was proposed to explain the pathogenesis of T2DM that connects the disease to a state of subclinical chronic inflammation. ${ }^{12,13}$ Inflammation is a short-term adaptive response of the body elicited as a principle component of tissue repair to deal with injuries and microbial infections (eg, cold, flu, etc.). It can be also elevated in chronic conditions such as peripheral neuropathy, chronic kidney disease and fatty liver. While the influence of fats is well known (see below), current thinking suggests that abnormal levels of chemokines released by the expanding adipose tissue in obesity activate monocytes and increase the secretion of pro-inflammatory adipokines. Such cytokines in turn enhance insulin resistance in adipose and other tissues, thereby increasing the risk for T2DM..$^{14,15}$ Together, lipid toxicity and low-grade inflammation appear to be major assaults on insulin sensitivity in insulin-responding tissues..$^{11,16,17}$

Activation of innate immunity promotes various inflammatory reactions that provide the first line of defense the body invokes against microbial, chemical, and physical injury, leading to repair of damage, isolation of microbial infectious threats and restoration of tissue homeostasis. ${ }^{18,19}$ Inherited variations in the degree of innate immune response may determine the lifetime risk of diseases upon exposure to adverse environmental stimuli. ${ }^{20}$ Therefore, innate immune responses can be viewed as the outcome of interaction between genetic endowment and the environment. ${ }^{21}$ The systemic reaction of innate immunity, known as the 'acutephase response', follows exposure to an exogenous insult (such as a pathogen or dietary factor) which triggers the release of pro-inflammatory cytokines like tumor necrosis factor (TNF)- $\alpha$, interleukin (IL)- $1 \beta$ and IL-6. ${ }^{22}$ These cytokines are derived primarily from macrophages and can directly enhance insulin resistance in adipocytes, muscle and liver cells. ${ }^{11,17}$ Macrophages infiltrate the expanding adipose tissue in obesity to remove dying cells and contribute to tissue angiogenesis. ${ }^{23}$ The adipose tissue of obese rodents and humans is indeed excessively infiltrated by macrophages and dendritic cells. ${ }^{11}$ Subsequent activation of macrophages towards an inflammatory phenotype results in cytokine synthesis and release. ${ }^{24,25}$ Cytokines then downregulate major anabolic cascades involved in insulin signaling and mediate adipocyte insulin resistance. ${ }^{24,25}$ Ultimately, this contributes to disruption of whole-body insulin sensitivity and impairs glucose homeostasis. ${ }^{26}$

In addition to their effect on insulin resistance, cytokines also act on the liver to increase the production of very-low density lipoproteins (VLDL), leading to the characteristic diabetic dyslipidemia, ${ }^{27}$ and to stimulate the hepatic production of fibrinogen, an atherosclerotic risk factor. ${ }^{12}$ Furthermore, cytokines deactivate the liver X receptors (LXR), resulting in an increased rate of cholesterol accumulation, ${ }^{28}$ and ultimately trigger the hepatic production and secretion of acute-phase proteins such as C-reactive protein (CRP), plasminogen activator inhibitor-1 (PAI-1), serum amyloid-A, $\alpha 1$-acid glycoprotein, and haptoglobin (collectively known as inflammatory factors or markers) into the circulation. The synthesis of acute-phase reactants following the cytokine release characterizes the pre-clinical (or early) stages of T2DM ${ }^{21}$ and exhibits graded increases as the disease progresses and clinical complications ensue ${ }^{12}$ (see below).

Extensive experimental, clinical and epidemiological studies have linked obesity causally to the activation of inflammatory signaling pathways and to the subsequent manifestations of T2DM. ${ }^{7,29,30}$ This relationship may facilitate the development of preventive measures for the disease at the early stages, as well as its main antecedent, obesity. For example, pharmaceutical and nutritional factors that reduce inflammation and the ensuing acute-phase reactant responses could be employed to improve insulin sensitivity and delay disease onset. ${ }^{31-33}$ Furthermore, a subset of the pro-inflammatory cytokines and inflammatory factors may provide a phenotypic profile that can be utilized as a sensitive and specific composite biomarker for early detection of risk to T2DM. Taken together, these approaches may aid in reducing the rising rates of disease incidence and better address issues related to prevention and treatment.

This review was undertaken to examine current knowledge linking inflammatory signaling pathways within the innate immune system to the risk of T2DM. The possibility that inflammatory markers could serve as molecular targets for prevention and/or biomarkers for early risk prediction of T2DM is evaluated in the context of enhancing public health strategies for diabetes prevention and control.

\section{Obesity, T2DM, and inflammation: Molecular mechanism(s) of association}

In obese people, insulin resistance is linked to the increased release of adipocyte-derived bioactive metabolites (ADBMs) 
such as lipids, free fatty acids, monocyte chemoattractant protein-1 (MCP-1), and pro-inflammatory cytokines. ${ }^{30}$ It should be emphasized, however, that although obesity is viewed as a predisposing factor to insulin resistance, other factors may also contribute. A study of young, insulin-resistant, lean offspring of patients with T2DM and insulin-sensitive controls of similar body mass index (BMI) showed similar plasma concentrations of TNF- $\alpha$, IL- 6 , and adiponectin between the insulin-resistant and insulin-sensitive groups. ${ }^{34}$ This suggests that in lean people, systemic inflammation may not play a significant role in the development of insulin resistance. In this case, proposed mechanisms for insulin resistance might then be attributed to a dysregulation of intramyocellular fatty acid metabolism. ${ }^{14}$ In the liver this would also include an altered expression of transcription factor $6-\alpha$ (ATF6) which controls expression of gluconeogenic genes. ${ }^{35}$ Genetic predisposition also may contribute to the development of T2DM. Genome-wide association (GWA) and candidate gene studies over the past few years have so far uncovered 19 genes associated with T2DM. ${ }^{36}$ The disease-related genetic variants identified have high frequencies in the populations assessed although their individual contributions to increases in risk of T2DM are modest. Ongoing GWAs that target lowfrequency genetic variants and assess copy number variants (CNVs) in addition to single nucleotide polymorphisms (SNPs) are likely to identify additional loci associated with T2DM risk, and some of these may play a significant role in the risk of disease development. ${ }^{36}$ In lean subjects with T2DM, the dysregulation of fatty acid metabolism, the abnormal expression of gluconeogenic genes and the genetic predisposition necessitate the development of an additional set of biomarkers that target this subpopulation and relate to these risk factors.

In the obesity-related insulin resistance, once adipocytes are activated (ie, accumulate fat and exhibit caloric excess), they release abnormal levels of ADBMs, leading to the recruitment of monocytes within adipose tissues. ${ }^{30}$ Monocyte differentiation into the macrophages lineage results in additional increases in the release of inflammatory factors and chemokines, propagating inflammatory responses both locally within adipose tissue and systemically elsewhere. ${ }^{14,17,30}$ In both human ${ }^{37}$ and anima $1^{16}$ models, $T N F-\alpha$ gene expression is upregulated in adipose tissues during obesity, linking pro-inflammatory substances released from adipose tissues to insulin resistance in T2DM.

The role for pro-inflammatory cytokines in regulating insulin action and glucose homeostasis and their function in T2DM has been suggested by several lines of evidence.
For example, compared to healthy individuals, subjects with T2DM risk factors such as obesity, hyper-triglyceridemia, or low high-density lipoprotein (HDL)-cholesterol exhibit higher serum levels of pro-inflammatory cytokines and acute-phase reactants than those who are not so predisposed. ${ }^{13}$ Cytokines also show a gradual increase as the disease progresses to its complications. ${ }^{13}$ Additionally, numerous prospective trials demonstrate that initial high levels of pro-inflammatory factors are associated with the manifestations of the disease. ${ }^{38-43}$ Baseline circulating concentrations of IL-6, PAI-1, CRP, and fibrinogen were significantly higher in healthy subjects who became diabetic later in life (ie, after 4-10 years) compared to those who did not develop the disease ${ }^{38-43}$ Furthermore, exogenous administration of TNF- $\alpha$ or IL- 6 results in insulin resistance, ${ }^{16,17,37}$ whereas low serum levels of cytokine in knock-out mice ${ }^{17,44}$ or treatment with anti-TNF- $\alpha$ agents, ${ }^{31}$ improved insulin sensitivity and glucose homeostasis. However, TNF- $\alpha$ is unlikely to be the only culprit for inducing insulin resistance and indeed many cytokines may act in synchrony to elicit the condition. Taken together, these observations suggest that inflammation is a feature when IGT develops at the pre-clinical stages of T2DM, perhaps at the overweight or obesity (see below).

The mechanisms that govern the association between the increased synthesis of inflammatory factors and T2DM are still being elucidated. In macrophages, adipocytes, antigen-presenting B-cells, dendritic cells, and Kupffer cells in the liver, a number of germline-encoded pattern recognition receptors (PRRs), such as the toll-like receptors (TLR), are activated upon ligand binding with conserved structural motifs that are either specific patterns of microbial components (eg, bacterial lipopolysaccharide [LPS] $)^{45}$ or nutritional factors (eg, free fatty acids [FFAs]). ${ }^{11,18,46-48}$ Binding to PRRs gives rise to inflammatory responses by mediating downstream transcriptional events that activate nuclear factor- $\kappa \mathrm{B}(\mathrm{NF} \kappa \mathrm{B})$ and activator protein-1 (AP-1) and their pathways (see Figure 1). ${ }^{19}$ Upon activation, these intracytoplasmic molecular cascades upregulate the transcription of pro-inflammatory cytokine genes ${ }^{22}$ and, consequently, the synthesis of acute-phase inflammatory mediators ${ }^{49-51}$ and activation of c-Jun N-terminal kinase (JNK) and inhibitor of NFKB kinase- $\beta$ (IKK). In liver and adipose tissue, these two molecules can inactivate the first target of the insulin receptor (INSR), IRS-1, thereby reducing downstream signaling towards metabolic outcomes. ${ }^{52,53}$ The interrelationship between these molecular targets suggests the expression and action of PRRs are the primary effector molecules in a downstream cascade that initiate dysregulation of 


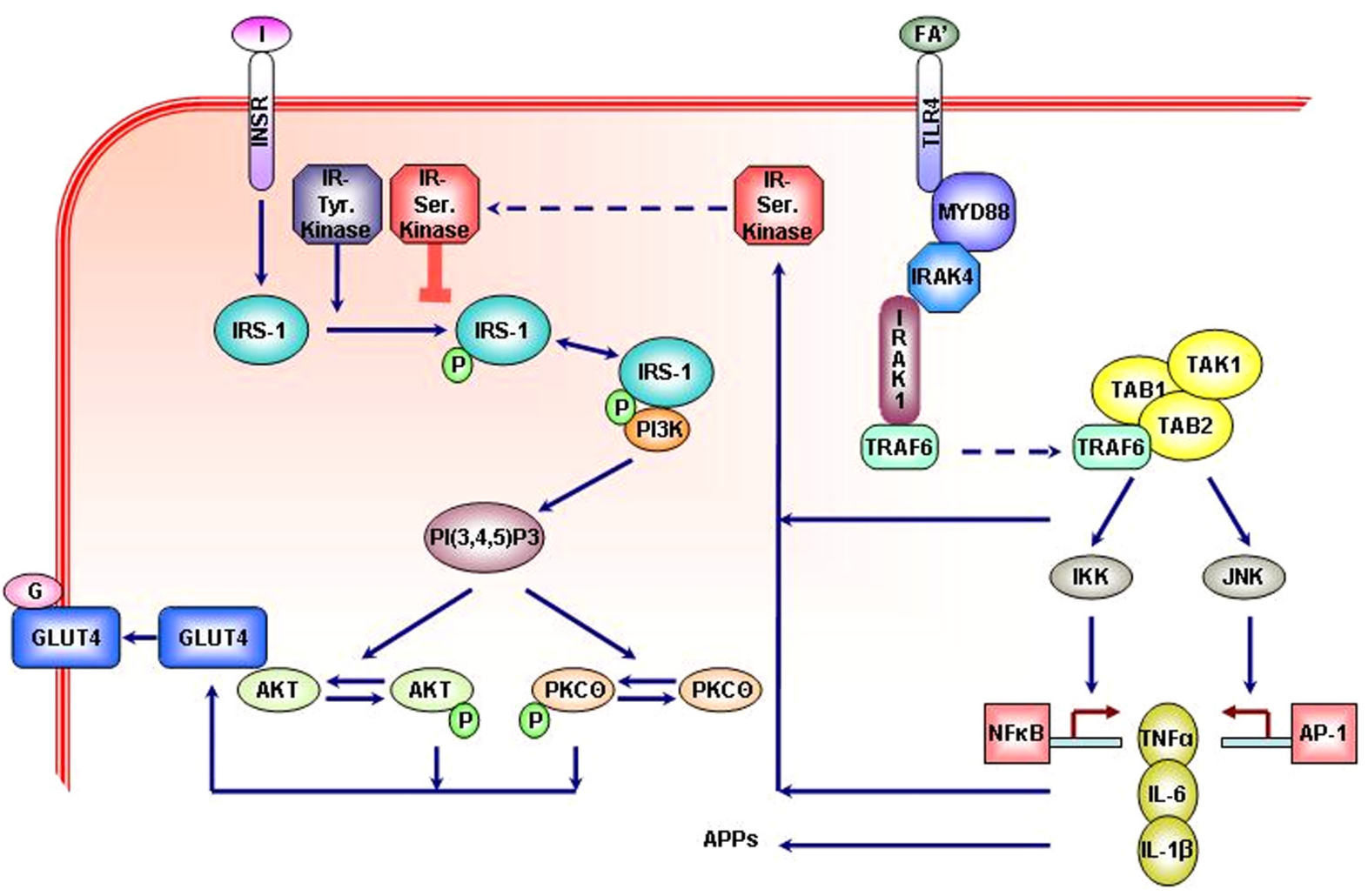

Figure I The interaction between insulin signaling and fatty acids in the synthesis of pro-inflammatory cytokines and inflammatory markers.

Notes: Current information suggests that insulin activates INSR to stimulate the phosphorylation of multiple tyrosine residues in the IRS and promote diverse biological responses. Illustrated here is the response of stimulation of glucose transport into muscle and fat cells. Activation of TLR4 by fatty acids initiates intracytoplasmic signals that activate the JNK-AP-I and IKK-NFKB axes which in turn increase the expression of cytokine-encoding genes. Cytokines initiate the hepatic production of APPs (eg, CRP, fibrinogen, haptoglobin, etc.) and dysregulate the INSR-IRS-mediated glucose transport into promoting serine phosphorylation of IRS that in turn reduces its tyrosine phosphorylation and, thereby, disrupts the insulin action.

Abbreviations: AKT, protein kinases B (PKB); AP-I, activator protein-I; APPs, acute phase proteins; G, glucose; GLUT4, glucose tansporter-4; I, insulin; IKK, inhibitor of NFKB kinase- $\beta$; IL-I $\beta$ and -6, interleukin-I $\beta$ and -6; INSR, insulin receptor; IRAKI and 4, interleukin-I receptor-associated kinase I and 4; IRS, insulin substrate; JNK, c-Jun amino-terminal kinase; MyD88, myeloid differentiation primary response gene-88; NFKB, nuclear factor $\kappa \mathrm{B}$; PI3K, phosphoinositide-3 kinase. PI(3,4,5)P3, Phosphatidylinositol 3,4,5-trisphosphate. PKC, protein kinase C. TAB, TAK binding protein. TAKI, mitogen-activated protein kinase kinase kinase (MAPKKK). TLR4, toll-like receptor-4; TNF $\alpha$, tumor necrosis factor- $\alpha$; TRAF6, TNF receptor-associated factor 6 .

insulin homeostasis. Therefore, altered expression/action, eg, as a result of SNP, in these PRRs may be employed to predict the possible development of T2DM (or earlier predisposing conditions) upon exposure to high levels of their ligands.

In addition to the activation of inflammation signals, strong evidence supports a direct role of FFAs in promoting insulin resistance. This has been ascribed to actions of their intracellular metabolites, primarily ceramide and diacylglycerol, on proteins that impinge on insulin-derived signals. Mixtures of FFAs arterially injected in vivo induced the activation of protein kinase $\mathrm{C}$ (PKC)- $\Theta$ or JNK in skeletal muscle. ${ }^{11,17,52}$ PKC- $\Theta$, like JNK, can inactivate IRS-1 and its downstream signaling towards metabolic outcomes. ${ }^{52}$ This is achieved by distinct serine phosphorylation of IRS-1 that reduces the signal-bearing tyrosine phosphorylation..$^{29}$ In contrast, saturated FFAs act largely to produce ceramides that spare IRS-1 but still inhibit insulin action downstream, at the level of the serine/threonine kinase Akt to also inhibit metabolic outcomes. ${ }^{54,55}$ Interestingly, direct exposure of insulin-target cells to cytokines such as TNF- $\alpha$ and IL-1 $\beta$ also activates JNK and IKK, ${ }^{56}$ making these factors a common link in the molecular mechanism of lipotoxicity and inflammation leading to insulin resistance and T2DM via post-transcriptional actions. ${ }^{53}$ Indeed, heterozygous deletion in $\operatorname{IKK} \beta$ (ie, in $\operatorname{IKK} \beta^{+/-}$mice) improved insulin sensitivity in obese mice target cells. ${ }^{57}$ In addition, TNF- $\alpha$ upregulates the expression of suppressor of cytokine signaling (SOCS) proteins, which bind to IRS- 1 to mediate its degradation. ${ }^{58}$ Furthermore, cytokine-mediated transcriptional up-regulation of JNK and IKK increases the expression of AP-1 and NF KB ${ }^{59}$ that, in turn, activate TNF- $\alpha$ to further propagate local and systemic inflammatory responses. ${ }^{60}$ Hence, JNK-AP-1 and IKK-NFאB are the major inflammatory pathways that disrupt insulin signaling via a series of transcriptional events and can be potentially modulated to improve insulin sensitivity and glucose homeostasis. ${ }^{17}$ 
An additional and highly relevant interaction between lipids and inflammation is the recent discovery that FFAs can directly activate macrophages to produce cytokines that render muscle cells insulin resistant. ${ }^{11,61}$ Such studies in cell culture are proof of principle that elevated FFAs can activate cells of the innate immune system to provoke muscle cell insulin resistance. In this case, both the macrophages and muscle cells showed activated JNK and IKK.

\section{Inflammatory network: Biomarkers of T2DM}

It is estimated that up to $25 \%$ of patients with newly diagnosed T2DM already present evidence of systemic inflammation at the time of diagnosis, ${ }^{62}$ suggesting that the disease (or the hypertriglyceridemia) has been present already for years since the development of status that predisposes to the disease (eg, overweight; see Figure 2). ${ }^{63-65}$ Current approaches to diabetes screening include determination of an elevated fasting plasma glucose level $(\geq 126 \mathrm{mg} / \mathrm{dL}$, ie, $7.0 \mathrm{mmol} / \mathrm{L}$ ) on two occasions, or an oral glucose tolerance test (OGTT) yielding $\geq 200 \mathrm{mg} / \mathrm{dL}(11.1 \mathrm{mmol} / \mathrm{L})$ after $2 \mathrm{~h}$, or symptoms of uncontrolled diabetes with a random plasma glucose level $\geq 200 \mathrm{mg} / \mathrm{dL}(11.1 \mathrm{mmol} / \mathrm{L})$. In addition, a score of glycosylated hemoglobin levels above $7 \%\left(\mathrm{HbA}_{1 \mathrm{c}} \geq 0.07\right)$ has been suggested as evidence of disease. ${ }^{4}$ None of these techniques has been found to detect all incident cases of T2DM and there is still a need to establish more sensitive and specific predictors of early risk ${ }^{66}$ Although inherited dysfunction in insulin signaling plays a role in the risk of T2DM, it is likely that any genetic component will be modified by environmental factors. Capturing the contribution of these genetic factors and their interaction with environmental covariates (eg, diet, physical activity, etc.) in the development of T2DM may provide an effective approaches for early detection and prevention. ${ }^{66,67}$

Inherited variations such as SNPs or CNVs in genes encoding for innate immunity-related inflammation may play a pivotal role in the susceptibility to T2DM and an array of chronic diseases ${ }^{68-72}$ Genetic polymorphisms, in conjunction with various environmental factors, may affect serum levels of cytokines and inflammatory markers and the subsequent risk of T2DM ${ }^{68-71}$ (see Table 1). Identification of SNPs or CNVs of inflammation-related genes, their frequencies and their association with risk of T2DM will assist in defining the genetic basis of the disease and early detection of risk.

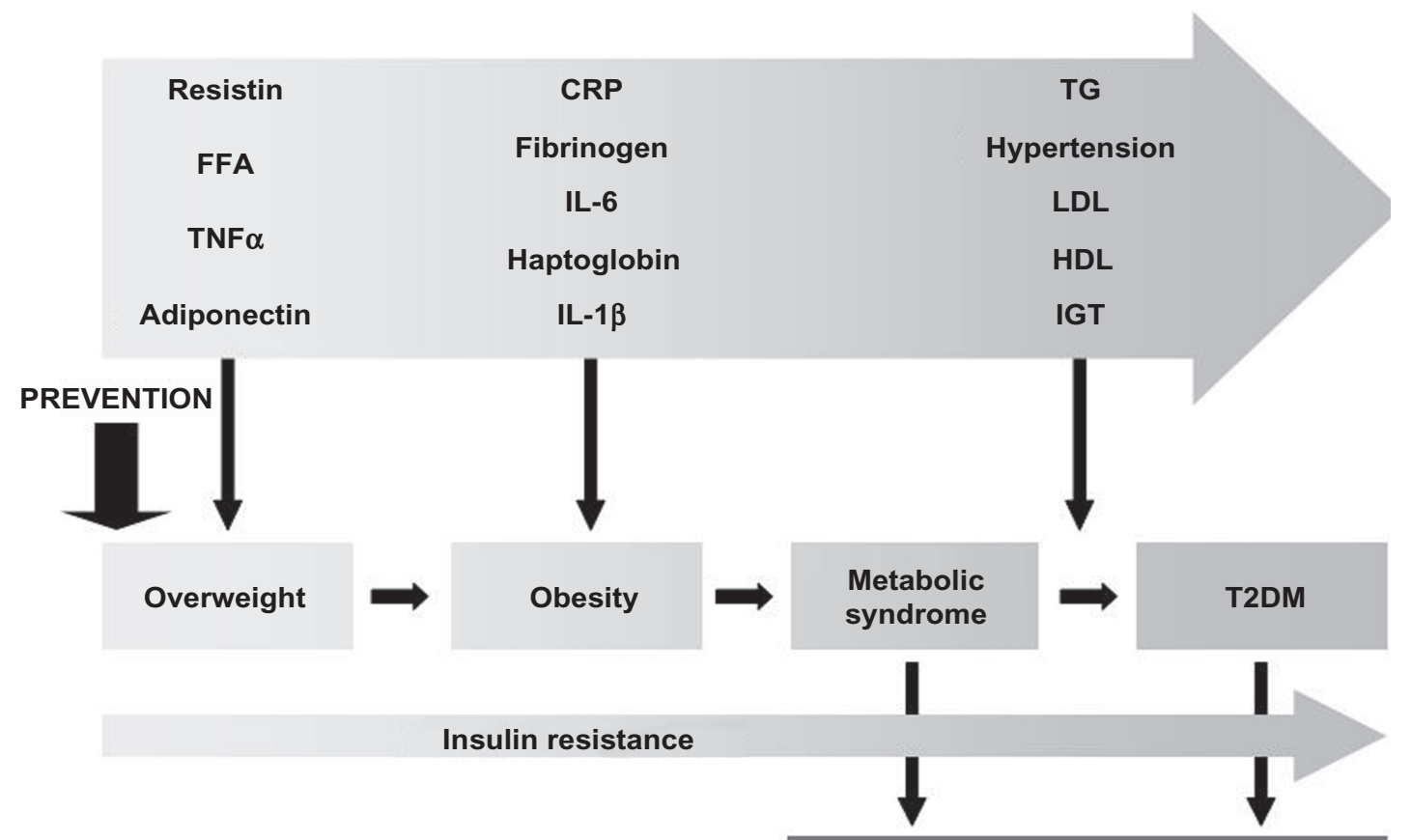

Cardiovascular disease

Figure 2 The relationship of inflammatory markers and disease factors to specific stages pathologic continuum from overweight to T2DM and cardiovascular diseases. ${ }^{63,64}$ Note: Depicted are the increases or decreases (see text) in relative values of various inflammatory markers and disease factors that take place as overweight progresses towards T2DM.

Abbreviations: CRP, C-reactive protein; FFA, free fatty acids; IGT, impaired glucose tolerance; IL, interleukin; HDL, high-density lipoprotein; LDL, low-density lipoprotein; TG, triglycerides; T2DM, type 2 diabetes mellitus. 
Table I Selected pro-inflammatory cytokine gene polymorphisms positively associated with T2DM and related risk factors and clinical complications ${ }^{68-72 a}$

\begin{tabular}{|c|c|}
\hline Condition $^{\mathrm{b}}$ & SNP \\
\hline BMI & IL-6 - I74C> G, IL6 CA rep., TNF $\alpha-308 G>A$ \\
\hline IGT & IL-6 $-I 74 C>G$ \\
\hline Insulin resistance & IL-6 - I 74C > G, TNF $\alpha-308 G>A$ \\
\hline Obesity & IL-6 - I 74C > G, IL6R 394T > G, TNF $\alpha-308 G>A$ \\
\hline T2DM & $\begin{array}{l}\text { IL-6 }- \text { I 74C }>\text { G, IL6R 48867A }>\text { G,TNF } \alpha \\
-308 G>A, \text { TNF } \alpha-863 C>A\end{array}$ \\
\hline Diabetic nephropathy & IL-6 -634C > G, ILI $\beta-5$ I IC $>T$ \\
\hline
\end{tabular}

Note: ${ }^{a} \mathrm{~A}$ selected list of SNPs positively linked to T2DM and related conditions was presented.

Abbreviations: BMI, body mass index; IGT, impaired glucose tolerance; IL, interleukin. rep., repeats; TNF $\alpha$, tumor necrosis factor- $\alpha$;T2DM, type 2 diabetes mellitus.

The feasibility of utilizing inflammatory markers in screening T2DM risk can be substantiated from numerous experimental, clinical and epidemiological observations demonstrating: a) the ability of inflammatory factors to predict the disease independently from established risk factors, ${ }^{73-76} \mathrm{~b}$ ) their link to one another by virtue of their common action, and c) the availability of quantitative, lessinvasive methods of assay, that would allow for repeated measurements. These characteristics render inflammatory mediators as potential candidates for a panel of powerful biomarkers for predicting T2DM incidence. As indicated in Figure 2, overweight sets the stage for low-grade chronic inflammation, with adiponectin levels decreasing while resistin, FFAs and TNF- $\alpha$ increase. As overweight progresses to obesity, continued inflammation further leads to elevated CRP, fibrinogen, IL-6, IL-1 $\beta$ and haptoglobin. Obesity can be complicated by metabolic dysregulation (metabolic syndrome) to develop frank T2DM where LDL-cholesterol and triglyceride levels increase, HDL-cholesterol levels deceases and hypertension and IGT manifest. $929,30,65,66,77$ Throughout the pathologic continuum from overweight to T2DM, insulin resistance increases progressively and the risk of cardiovascular disease (CVD) elevates. Metabolic syndrome is associated with about twofold increased susceptibility to CVD whereas T2DM is linked to fourfold higher risk. ${ }^{63,64}$ Public health initiatives aimed at preventing and controlling T2DM should be targeted towards the early stages of the disease, to prevent obesity and the cascade of inflammatory events that eventually leads to the clinical manifestation of T2DM. We next discuss the characteristics of cytokines and chemokines with potential to become biomarkers of inflammation and insulin resistance associated with obesity, ie, early T2DM risk detection.

\section{TNF- $\alpha$}

TNF- $\alpha$ is a primary mediator of many of the systemic acute responses related to severe infections with gramnegative bacteria. ${ }^{78}$ The major cellular source of TNF- $\alpha$ is activated mononuclear phagocytes, antigen-stimulated T-cells, natural killer (NK) cells, and mast cells. The TNF- $\alpha$ gene is constitutively expressed in adipose tissue, where it originates principally from macrophage infiltration rather than from the adipocytes themselves. ${ }^{16}$ In adipose tissue from obese subjects, TNF- $\alpha$ mRNA expression is 2.5 -fold higher than in lean subjects and is strongly correlated with hyperinsulinemia. ${ }^{26}$ Body weight reduction in obese people ${ }^{26}$ and in vivo TNF- $\alpha$ inhibition ${ }^{16}$ significantly reduced serum TNF- $\alpha$ and improved insulin sensitivity. High TNF- $\alpha$ is related to the pathophysiology of insulin resistance and T2DM, ${ }^{45}$ possibly through its impact on IRS- 1 as discussed above, ${ }^{16,26,58,79}$ or by enhancing the apoptosis of pancreatic $\beta$-cells. ${ }^{80}$

The association of the TNF- $\alpha$ gene polymorphisms with T2DM has been extensively investigated but with conflicting results. Some studies demonstrate a strong association between $T N F-\alpha$ SNPs and T2DM ${ }^{81-83}$ (Table 1) whereas others show no relationship. ${ }^{84,85}$ Although a number of variants have been identified in the TNF- $\alpha$ gene, the functional SNPs rs361525 (-238 G>A) and rs1800629 (-308 G>A) were identified in the promoter region. The functionality of the variant $-308 \mathrm{~A}$ allele is related to a twofold increase in transcriptional activity compared to the wild-type allele. ${ }^{86}$ Interestingly, this variant was suggested to play a critical role in the genetic predisposition to excessive fat accumulation in women in early stages of obesity, ${ }^{82}$ and to predict the conversion from IGT to T2DM..$^{81}$ The rs 1800629 SNP exhibited a gene-gene interaction effect with the $I L-6$ rs 1800795 $(-174 \mathrm{C}>\mathrm{G})$ in the early risk prediction of T2DM. ${ }^{81}$ On the other hand, the rs 361525 is located in a repressor site of the promoter, a $10 \mathrm{bp}$ sequence with homology to the binding site of the activator protein AP-2 regulating TNF- $\alpha$ function. ${ }^{87}$ Another SNP in TNF- $\alpha$ which was recently reported to be associated with increased risk of T2DM, is rs 1800610 $\left(\right.$ IVS1+123 G>A) ${ }^{83}$ The functional relevance of this SNP pertains to the YY1 transcription factor that binds specifically to the intron 1 region where the rs 1800610 resides and evokes increased TNF- $\alpha$ expression. ${ }^{83}$

\section{IL-6}

IL-6 is produced by many cell types including fibroblasts, endothelial cells, and monocytes-macrophages. ${ }^{88,89}$ However, a significant proportion of the circulating IL-6 (15\%-30\%) 
derives from adipose tissue production in the absence of acute inflammation ${ }^{90}$ to modulate adipocyte glucose and lipid metabolism..$^{91,92}$ In obesity, IL-6 synthesis is upregulated in adipocytes ${ }^{88,93}$ and correlates with circulating IL- $6{ }^{94}$ and with the extent of insulin resistance. ${ }^{77,93,95}$ IL-6 also triggers the hepatic synthesis of CRP and correlates with its serum levels. ${ }^{94,95}$ Additionally, IL-6 promotes hepatic VLDL secretion and hypertriglyceridemia. ${ }^{27,96}$ These observations suggest a link between IL-6 levels, obesity and inflammation in the pathogenesis of T2DM ${ }^{97}$ and demonstrate that IL- 6 can be considered as a candidate biomarker for early T2DM risk detection.

Several mechanisms have been proposed to explain how IL-6 can mediate insulin resistance..$^{17,56,77,93,95,98}$ The IL-6 receptor (IL6R) belongs to the cytokine class I receptor family that includes the JNK signal transduction pathway. ${ }^{53,99}$ JNK activation by IL-6 induces STAT (signal transducers and activators of transcription) phosphorylation, dimerization, and translocation to the nucleus to regulate the transcription and function of an array of target genes including IRS, $A P-1$, and $N F \kappa B^{53,59}$ in hepatocytes and adipocytes. ${ }^{100}$ Transcriptional upregulation of these genes promotes both localized and systemic inflammatory responses ${ }^{60}$ to mediate fatty liver and insulin resistance. ${ }^{101}$ The interaction between IL-6 and the insulin pathway also involves mediating the interaction between SOCS proteins and the INSR. ${ }^{102-104}$ Therefore, IL- 6 antagonists and factors that target JNK and IKK may offer promising preventive and/or therapeutic approaches to improve insulin sensitivity. ${ }^{32,105}$

In humans, numerous studies have demonstrated that elevated levels of IL-6 are associated with an increased incidence of T2DM independent of obesity ${ }^{73-76}$ or fasting insulin levels. ${ }^{74}$ The relative risk of the disease for individuals with IL-6 levels in the highest tertile (vs lowest tertile) was 2.02 (95\% confidence interval [CI]: 1.14-3.58), after adjustment for BMI, lifestyle factors, and pre-existing CVD. ${ }^{73}$ Furthermore, chronically elevated IL- 6 was related to a range of metabolic abnormalities typical of an insulin resistant state. ${ }^{97}$ Several polymorphisms exist in the $I L-6$ and IL6R (Table 1). Two common SNPs in the promoter region of IL-6, rs1800795 (-174 G>C) and rs1800796 (-572 G>C) were examined for their role in predisposition to T2DM. These SNPs were investigated in a large meta-analysis of $>20,000$ participants from 21 published and unpublished studies for their association with T2DM. ${ }^{106}$ The allele $-174 \mathrm{C}$ was associated with reducing the risk of T2DM by nearly $10 \%$ (odds ratio $[\mathrm{OR}]=0.91 ; P<0.037$ ) and exhibited a gene-gene interaction with the TNF- $\alpha$ rs1800629 in predicting disease risk. ${ }^{81}$ No evidence for association was found, however, between rs 1800796 and T2DM. ${ }^{106}$ Overall, these findings, although indicative of a role for IL-6 polymorphisms in T2DM, suggest that additional studies are needed to confirm this association, particularly in relation to other genes along the innate immunity and inflammatory pathways. Moreover, studies that examine gene-environment interactions may yield more meaningful results and provide important insights into the role of IL-6 in the pathogenesis of T2DM as well as its value as a biomarker of early disease risk detection.

\section{CRP}

CRP is an acute-phase reactant produced primarily in the liver under the stimulation of adipocyte-derived IL-6 and TNF- $\alpha$. It exhibits several characteristics that imply a fundamental immunoregulatory function. Specifically, CRP is a member of the pentraxin family of oligomeric proteins involved in PRRs activation. CRP also enhances leukocyte reactivity, complement fixation, modulation of platelet activation, and clearance of cellular debris from sites of active inflammation..$^{50,107}$ The magnitude and rapidity of its induction and its cooperative role in innate immune response, as well as its ease of measurement, all make CRP a common marker for inflammation. ${ }^{108}$ Furthermore, CRP is invariably correlated with various parameters relevant to diabetes, including obesity, lipogenesis, and adiponectin. ${ }^{66}$ In this respect, CRP was shown to be consistently associated with the incidence of T2DM in populations of otherwise healthy persons. ${ }^{66,109} \mathrm{~A}$ recent study estimated that one-third of T2DM cases can be associated with elevated serum CRP. ${ }^{109}$ Although the relationship between CRP and T2DM was thought to be stronger in women than men, ${ }^{42}$ subjects of both sexes with high serum CRP $(>2.6 \mathrm{mg} / \mathrm{L})$ had more than double the overall T2DM risk $(\mathrm{OR}=2.37 ; 95 \% \mathrm{CI}: 1.57-3.58)$ compared to those with levels of $<0.5 \mathrm{mg} / \mathrm{L} .{ }^{109}$ Together, these findings substantiate a role for CRP as a possible candidate biomarker for early T2DM risk detection.

Numerous prospective studies demonstrate an independent positive association of CRP with the presence of T2DM ${ }^{38,75,76,109-114}$ while others show no association after adjustment for adiposity and insulin resistance. ${ }^{39,41,74,115}$ A meta-analysis of available data from 10 prospective studies showed a positive association between serum CRP and T2DM independent of obesity. ${ }^{109}$ Another meta-analysis of 16 published studies with 3,920 T2DM cases and 24,914 controls demonstrated a relative risk (RR) of T2DM of $1.72(95 \%$ CI: 1.54-1.92) for subjects with high CRP levels. ${ }^{116}$ A major 
mechanism by which CRP plays a critical role in T2DM is primarily by its action on pancreatic $\beta$-cell. ${ }^{117,118}$ For example, CRP significantly inhibits cell proliferation and increases the rates of apoptotic cell death. ${ }^{119}$ This effect was connected to the CRP-mediated modulation of protein kinase B (PKB), a key factor for cell survival pathways and to its ability to induce the production of TNF- $\alpha$, IL- $1 \beta$ and matrix metalloproteinase- 9 (MMP-9) in a concentration-dependent manner. ${ }^{119}$

Several SNPs were identified in the CRP gene and were linked to elevated levels of serum CRP, ${ }^{120}$ low insulin sensitivity, ${ }^{121}$ and incidence of T2DM. ${ }^{122-124}$ Among these SNPs, the variants rs3093059 $(-757 \mathrm{~A}>\mathrm{G})^{120,121,123}$ and rs2794521 $(-717 \mathrm{~A}>\mathrm{G})^{120-123}$ were extensively studied and were reported to be associated with an increased risk of T2DM. Furthermore, CRP SNPs at the 3' end-rs1800947 (1059 $\mathrm{G}>\mathrm{C})$ and rs1130864 (1444 C>T)-were associated with decreased and increased concentrations of CRP, respectively. ${ }^{125}$ Several studies demonstrate that serum CRP can be additively influenced by the $I L-6-C R P$ gene-gene interaction. ${ }^{126-129}$ Increased serum CRP in obese individuals was correlated with elevated secretion of IL- 6 and TNF- $\alpha$ in adipocytes and predisposes to the chronic inflammatory state associated with T2DM. ${ }^{21}$

Overall, evaluating the effect of inflammatory factors in T2DM may provide new public health approaches for disease prevention and a novel strategy for early detection. These markers are evidently related to risk of T2DM and can be employed in early detection of disease risk and as a predictive measure of response to preventive intervention. If the extent of interaction between the genetic (eg, polymorphisms in $T N F-\alpha, I L-6$, and $C R P$ genes), biochemical (eg, serum levels of TNF- $\alpha$, IL- 6 , and CRP), and environmental (eg, micronutrient supplementation) factors and the risk of T2DM can be established, a selected set of innate immunity-related inflammatory markers could become a powerful panel of integrated multiplex biomarkers for the early risk detection of T2DM. This integration may permit maximizing the sensitivity, specificity, and predictability of biomarkers to T2DM in the general population. A set of inflammatory markers could be utilized to develop effective and novel strategies for disease intervention based on supplementation with micronutrients that modify (ie, lower) their gene expression or serum levels (see below).

\section{Attenuating inflammatory response in T2DM by micronutrients}

Factors that attenuate inflammation (and the inflammatory markers proposed above, such as TNF $\alpha$, IL-6, and CRP) could provide an important public health tool to reduce the burden of diseases related to this pathway, such as obesity, T2DM and cardiovascular diseases, in the general population. The feasibility of modulating innate immunity-related inflammation as an approach for the prevention of T2DM is based on reports that evaluated the efficacy of antiinflammatory pharmaceutical agents on disease manifestation and outcome. ${ }^{14,32,105}$

The major current therapeutic agents to treat T2DM, sulfonylureas, metformin, and insulin-sensitizing glitazones, all improve metabolic control and lead to normalization of circulating inflammation markers through, at least partly, interaction with the innate immunity-related pathway. Sulfonylureas increase insulin release from pancreatic $\beta$-cells, ${ }^{130}$ whereas metformin suppresses glucose production in the liver and increases insulin sensitivity in peripheral tissues. ${ }^{131}$ Glitazones bind to peroxisome proliferator-activated receptors (PPARs), initiating transcriptional activity that leads to improved insulin action. ${ }^{132}$ While not necessarily acting primarily to reduce inflammation, it is likely that these drugs' correction of glucose and insulin levels impinges on the innate immune system, attenuates inflammation and further improves insulin action. Accordingly, glitazones reduced serum levels of CRP (30\% reduction in 1 week), PAI-1, TNF- $\alpha$ and other inflammatory markers. ${ }^{7,133}$ Statins, metformin and sulfonylureas have comparable anti-inflammatory activity. $8,9,134$

A therapeutic strategy for T2DM that would act primary on the inflammatory system has been proposed in the form of salicylates, an anti-inflammatory agent that inhibits IKK ${ }^{135}$ and is long known to have a hypoglycemic effect. ${ }^{136,137}$ Nonsteroidal anti-inflammatory drugs (NSAIDs) and cyclooxygenase inhibitors are able to enhance glucose-induced insulin release, improve glucose tolerance, and increase the effect of insulin in patients with T2DM. ${ }^{17,29,105}$ In humans, treatment with NSAIDs improved various biochemical indices associated with T2DM (Table 2). Although these observations support the notion that inflammation plays a pivotal role in T2DM, attenuating inflammation as a strategy for disease prevention in a public health setting will necessitate a substantially different perspective. In this case, a strategy that can be introduced into the general population with the least (if any) side effects and the maximal preventive outcome should be adopted. In this context, a nutritional intervention approach would be a desirable option.

In general, studies in animal models and humans have demonstrated that disrupting the IKK $\beta-N F \kappa B$ pathway improves obesity-related insulin sensitivity. ${ }^{14}$ Furthermore, 
Table 2 Effect of attenuating inflammation by anti-inflammatory factors on biochemical measures of predisposition to T2DM ${ }^{105 a}$

\begin{tabular}{lll}
\hline Characteristic & Effect $^{\mathrm{b}}$ & $\%$ Change $^{\mathrm{c}}$ \\
\hline Fasting plasma glucose & $\downarrow$ & 25 \\
Basel hepatic glucose production & $\downarrow$ & 20 \\
Glucose uptake & $\uparrow$ & 20 \\
Insulin-stimulated peripheral glucose uptake & $\uparrow$ & 20 \\
Insulin clearance & $\downarrow$ & 30 \\
Total cholesterol & $\downarrow$ & 15 \\
Fatty acid levels & $\downarrow$ & 50 \\
Triglycerides & $\downarrow$ & 50 \\
CRP & $\downarrow$ & 15 \\
\hline
\end{tabular}

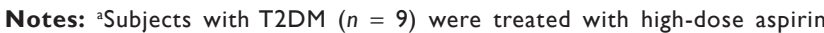

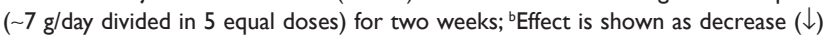
or increase $(\uparrow)$; ${ }^{c} C$ Changes represent the difference in biochemical measures (\%) before and after treatment.

Abbreviations: CRP, C-reactive protein;T2DM, type 2 diabetes mellitus.

blocking JNK activity in animal models of diabetes enhanced systemic glucose homeostasis and insulin sensitivity, ${ }^{32}$ whereas inhibition of IKK by salicylates led to an overall improved insulin action. ${ }^{105}$

Micronutrient, certain fatty acids (eg, omega-3 fatty acid) and/or trace element supplementation can modify innate immune-related responses and, subsequently, modify the risk of a range of chronic conditions. With respect to T2DM, the consensus of available information suggests that micronutrient intake modulates the innate immune system ${ }^{138}$ and can subsequently influence the predisposition to (and prevention of) disease. ${ }^{80,138,139}$ By virtue of this observation, the hope is that the outcome of nutritional supplementation can be simply monitored via its modifying action on the levels of inflammatory biomarkers. Many micronutrients exhibit well-characterized anti-inflammatory or immunomodulatory functions (see below). Vitamins (eg, D, E, and C), certain fatty acids (eg, omega-3 fatty acid) and trace elements (eg, selenium, zinc, copper and iron) are known to improve the overall function of the immune system, prevent excessive expression and synthesis of inflammatory cytokines, and increase the 'oxidative burst' potential of macrophages. ${ }^{138}$ Natural health products (NHPs) that contain pertinent micronutrients (eg, so-called adaptogenic medicinal plants) or modulate the innate immune system on their own (eg, omega-3 fatty acids and probiotics) also represent an interesting avenue to study, although the evidence base for their beneficial action is highly variable. ${ }^{140}$ Exploring the possibility that supplementation with selected micronutrients, trace elements and/or other NHPs can attenuate obesityrelated inflammation in order to delay the development of
T2DM should be considered alongside existing public health practices to reduce the rising incidence of the disease.

\section{Vitamin D}

Vitamin D insufficiency has been associated with a wide range of chronic diseases, including autoimmune diseases, atherosclerosis, cancer, obesity, cardiovascular diseases, and diabetes. ${ }^{141}$ In T2DM, the role of vitamin D was suggested from the presence of vitamin D receptors (VDR) in the pancreatic $\beta$-islet cells. ${ }^{142}$ In these cells, the biologically active metabolite of vitamin D (ie, 1,25-dihydroxy-vitamin D; $1,25(\mathrm{OH}) \mathrm{D})^{138}$ enhances insulin production and secretion via its action on the VDR. ${ }^{142}$ Indeed, the presence of vitamin D-binding protein (DBP), the principal predictor of serum levels of $25(\mathrm{OH}) \mathrm{D}$ and response to vitamin $\mathrm{D}$ supplementation, ${ }^{143}$ and VDR initiated several studies demonstrating a relationship between SNPs in the genes regulating $V D R$ and $D B P$ with glucose intolerance and insulin secretion. ${ }^{144-146}$ This further supports a role of vitamin D in T2DM and may explain the reduced overall risk of T2DM in subjects who ingest $>800 \mathrm{IU} / \mathrm{d}$ of vitamin D ${ }^{80,139}$ However, an alternative, and perhaps related, explanation was recently proposed based on the potent immunomodulatory functions of vitamin D. ${ }^{147-149}$ VDRs are present in most types of immune cells ${ }^{150}$ and 1,25(OH)D modulates the production of the immunostimulatory IL-12 and the immunosuppressive IL-10. ${ }^{151}$ In this respect, supplementation with vitamin $\mathrm{D}^{33}$ or its bioactive form $1,25(\mathrm{OH}) \mathrm{D}^{138}$ improved insulin sensitivity by preventing the excessive synthesis of inflammatory cytokines. This effect on cytokine synthesis is due to its interaction with vitamin D response elements (VDRE) present in the promoter region of cytokine-encoding genes. This interaction downregulates the transcriptional activities of cytokine genes and attenuates the synthesis of the corresponding proteins. ${ }^{33}$ Vitamin D also deactivates NFKB that transcriptionally regulates the pro-inflammatory cytokineencoding genes. ${ }^{152}$ Downregulating the expression of NFKB and downstream cytokine genes inhibits $\beta$-cell apoptosis and promotes their survival. ${ }^{33}$ Numerous intervention trials, clinical studies, and epidemiological findings demonstrated that supplementation with vitamin $\mathrm{D}$ can be beneficial in optimizing processes linked to T2DM such as insulin response, and hence, may markedly improve T2DM prevention strategies. ${ }^{80,142}$ For example, increasing intake of vitamin D to $>800$ IU daily, along with $1200 \mathrm{mg}$ of calcium, reduced the risk of developing T2DM by $33 \%{ }^{80}$ In agreement, healthy older adults with impaired fasting glucose showed significant improvement in glycemic and insulin responses when they 
increased their intake of vitamin D by $700 \mathrm{IU} /$ day and calcium by $500 \mathrm{mg} /$ day for three years. ${ }^{139}$ Therefore, exploring the possibility that vitamin $\mathrm{D}$ can modify the action of innate immunity genes to attenuate the T2DM-associated lowgrade chronic inflammatory response, and prevent disease development and/or progression, may represent an attractive approach for public health intervention, both in the general population as well as in vulnerable subpopulations. It should however, be considered that vitamin D serum levels, and subsequently extent of supplementation, will vary considerably depending on sunlight exposure; an observation that should be taken into account when employing it in public health intervention of T2DM.

\section{Vitamin E}

Vitamin E is known to have a significant impact on improving a variety of immune functions. ${ }^{153}$ Supplementation with vitamin $\mathrm{E}$ increases the rate of lymphocyte proliferation by enhancing the ability of $\mathrm{T}$ cells to undergo cell division cycles. ${ }^{154}$ The effective anti-inflammatory action of vitamin E was substantiated from observations such as the increased expression of the IL-2 gene and IL-1 receptor antagonist and the decreased expression of IL-4 following vitamin E supplementation in animal models. ${ }^{153}$ Furthermore, vitamin E reduced the serum levels of IL-1 $\beta$, IL-6, TNF- $\alpha$, PAI-1, and CRP in T2DM patients. ${ }^{155}$ These anti-inflammatory actions are thought to result from its inhibitory effect on the 5-lipoxygenase (5-LOX) at the post-transcriptional level. ${ }^{156}$ 5-LOX is a member of the lipoxygenase family of enzymes involved in the synthesis of the inflammatory prostaglandins. Additional anti-inflammatory functions of vitamin E include its downregulation of $\mathrm{NF} \kappa \mathrm{B}^{155}$ and its potent lipophilic antioxidant effect on internal and external cell membranes as well as plasma lipoproteins, notably LDL. Based on this latter characteristic, studies in both animal models and humans have demonstrated that vitamin E intake blocks LDL lipid peroxidation, prevents the oxidative stress linked to T2DMassociated abnormal metabolic patterns (hyperglycemia, dyslipidemia, and elevated levels of FFAs), and, subsequently, attenuates cytokine gene expression. ${ }^{153,155,157,158}$ Despite these findings, a recent study evaluated the effects of a combination of vitamin C (1000 mg/day) and vitamin E (400 IU/day) for four weeks on insulin sensitivity in untrained and trained healthy young men and concluded that such supplementation may preclude the exercise-induced amelioration of insulin resistance in humans. ${ }^{159}$ This may relate to the source of vitamin E used, ie, $\alpha$-, $\beta$ - $\gamma$-, or $\delta$-tocopherol. ${ }^{160}$ Nevertheless, in general, the immunomodulatory, anti-inflammatory and anti-oxidative functions of vitamin E strongly support its possible application in designing effective prevention and/or treatment protocols for T2DM. ${ }^{157}$

Current practices for diabetes prevention in the general population include lifestyle change, dietary intervention and exercise. As suggested above, micronutrient supplementation may aid in T2DM prevention and control through the anti-oxidant, anti-inflammatory and immunomodulatory properties of various vitamins and trace elements. It seems reasonable, therefore, to suggest that the two preventive approaches for T2DM (ie, micronutrient supplementation and lifestyle change) may be combined into a single program to enhance the success and effectiveness of intervention. This strategy could be more efficient in reducing the low-grade inflammation associated with pre-clinical T2DM and, subsequently the disease burden, than when a single approach is considered. Moreover, such a combined strategy can be introduced in general practice settings and in a population-based fashion with low expenditure and minimal side effects.

\section{Conclusions}

The current state of knowledge warrants further study into the extent of association between inflammatory markers and early stages of T2DM, on one hand, and the effect of micronutrients in modifying this relationship, on the other. Such an approach is critical to comprehensively evaluate the prospect of applying inflammatory network assessment in disease surveillance. A significant public health potential of developing this set of evidence-based biomarkers can be conceptualized from their application as precise genomic-based measures of risk prediction for T2DM beyond the simple risk factors presently employed, such as family history or physical examination. In this respect, inflammatory biomarkers may permit capturing the etiological function of (and interaction between) genetic constitution and environmental risk modifiers in the T2DM pathogenesis. Furthermore, a major benefit of introducing inflammatory markers into public health settings stems from their potential to facilitate developing a novel class of agents which attenuate low-grade inflammation prior to the clinical onset of T2DM and to be employed in disease prevention. However, before applying these biomarkers in public health, protocols for their assessment should be standardized and laboratory reference intervals need to be used in decision-making processes.

Employing this set of biomarkers in evaluating responses to prevention may necessitate examining the contribution of dynamic interaction between genetic and dietary modifiers in the etiology of T2DM, as well as the influence of these 
factors on inflammation at the early disease stages. It seems likely that micronutrient supplementation can modify the genotype-phenotype association within the innate immune response. This proposition may elucidate the mechanisms by which nutritional factors prevent or delay disease development and can be introduced into the general population and susceptible subpopulations. The efficacy of micronutrient supplementation to attenuate or balance the innate immune response and the ensuing inflammation first needs to be further explored and optimized; in some cases, this includes developing tools to accurately and reproducibly measure the circulating/tissue levels of potential biomarkers in order to relate it to clinical outcome. The impact of micronutrients on T2DM incidence may then be assessed through a series of pilot population-based studies: firstly, to determine the feasibility and effectiveness of this protocol; second, to validate and evaluate the strategy and ensure replication of results; and, third, to monitor the outcome to quantify the overall preventive response in comparison (and combination) with the current preventive approaches for T2DM such as lifestyle changes, exercise, and dietary intervention.

\section{Acknowledgments}

The authors would like to acknowledge the suggestions and input of Dr Linda Greene-Finestone and Dr Margaret de Groh of the Public Health Agency of Canada. The authors report no conflicts of interest in this work.

\section{References}

1. Wild S, Rolic C, Green A. Global prevalence of diabetes: Estimates for the year 2000 and projection for 2030. Diabetes Care. 2004;37:1047-1053.

2. Mokdad AH, Bowman BA, Ford ES, Vinicoor F, Marks JS, Koplan JP. The continuing epidemics of obesity and diabetes in the United States. JAMA. 2001;286:1195-1200.

3. Venkataraman R, Nanda NC, Baweja G, Parikh N, Bhatia V. Prevalence of diabetes mellitus and related conditions in Asian Indians living in the United States. Am J Cardiol. 2004;94:977-980.

4. Stumvoll M, Goldstein B, van Haeften T. Type 2 diabetes: principles of pathogenesis and therapy. Lancet. 2005;365:1333-1346.

5. Zimmet P, Alberti KG, Shaw J. Global and societal implications of the diabetes epidemic. Nature. 2001;414:782-787.

6. Alberti KG. Treating type 2 diabetes-today's targets, tomorrow's goals. Diabetes Obes Metab. 2001;3(Suppl 1):S3-S10.

7. Dandona $P, A l j a d a A$, Bandyopadhyay A. Inflammation: the link between insulin resistance, obesity and diabetes. Trends Immunol. 2004;25:4-7.

8. Dandona P, Aljada A. A rational approach to pathogenesis and treatment of type 2 diabetes mellitus, insulin resistance, inflammation, and atherosclerosis. Am J Cardiol. 2002;90:27G-33G.

9. Dandona P, Aljada A, Chaudhuri A, Bandyopadhyay A. The potential influence of inflammation and insulin resistance on the pathogenesis and treatment of atherosclerosis-related complications in type 2 diabetes. J Clin Endocrinol Metab. 2003;88:2422-2429.

10. Dimopoulos N, Watson M, Sakamoto K, Hundal HS. Differential effects of palmitate and palmitoleate on insulin action and glucose utilization in raty L6 skeletal muscle cells. Biochem J. 2006;399:473-481.
11. Bilan PJ, Samokhvalov V, Koshkina A, Schertzer JD, Samaan MC, Klip A. Direct and macrophage-mediated actions of fatty acids causing insulin resistance in muscle cells. Arch Physiol Biochem. 2009;115:176-190.

12. Pickup JC, Crook MA. Is type II diabetes mellitus a disease of the innate immune system? Diabetologia. 1998;41:1241-1248.

13. Pickup JC, Matttock MB, Chusney GD, Burt D. NIDDM as a disease of the innate immune system: association of acute phase reactants and interleukin-6 with metabolic syndrome X. Diabetologia. 1997;40:1286-1292.

14. King GL. The role of inflammatory cytokines in diabetes and its complications. J Periodontol. 2008;79:1527-1534.

15. Larsen GL, Henson PM. Mediators of inflammation. Annu Rev Immunol. 1983;1:335-359.

16. Hotamisligil GS, Shargill NS, Spiegelman BM. Adipose expression of tumor necrosis factor-alpha: direct role in obesity-linked insulin resistance. Science. 1993;259:87-91.

17. Hotamisligil GS. Inflammation and metabolic disorders. Nature. 2006;444:860-867.

18. Beutler B. Innate immunity: an overview. Mol Immunol. 2004;40:845-859.

19. Takeda K, Akira S. TLR signaling pathways. Seminars Immunol. 2004;16:3-9.

20. Le Souëf PN. Gene-environmental interaction in the development of atopic asthma: new developments. Curr Opin Allergy Clin Immunol. 2009;9:123-127.

21. Fernandez-Real JM, Pickup JC. Innate immunity, insulin resistance and type 2 diabetes. Trends Endocrin Metabol. 2007; 19:10-16.

22. Medzhitov R, Janeway C. Innate immunity. N Engl J Med. 2000; 343:338-344.

23. Pang C, Goa Z, Yin J, Zhang J, Jia W, Ye J. Macrophage infiltration into adipose tissue may promote angigenesis for adipose tissue remodeling in obesity. Am J Physiol Endocrinol Metab. 2008; 295:E313-E322.

24. Lumeng CN, Bodzin JL, Saltiel AR. Obesity induces a phenotypic switch of adipose tissue macrophage polarization. J Clin Invest. 2007; 117:175-184.

25. Lumeng CN, Deyoung SM, Bodzin JL, Saltiel AR. Increased inflammatory properties of adipose tissue macrophages recruited during diet-induced obesity. Diabetes. 2007;56:16-23.

26. Hotamisligil GS, Arner P, Caro JF, Atkinson RL, Spiegelman BM. Increased adipose tissue expression of tumor necrosis factor-a in human obesity and insulin resistance. J Clin Invest. 1995;95: 2409-2415.

27. Sjoholm A, Nystrom T. Inflammation and the etiology of type 2 diabetes. Diabetes Metab Res Rev. 2006;22:4-10.

28. Castrillo A, Joseph SB, Vaidya SA, et al. Crosstalk between LXR and Toll-like receptor signaling mediates bacterial and viral antagonism of cholesterol metabolism. Mol Cell. 2003;12:805-816.

29. Wellen KE, Hotamisligil GS. Inflammation, stress, and diabetes. J Clin Invest. 2005;115:1111-1119.

30. Shoelson SE, Lee J, Goldfine AB. Inflammation and insulin resistance. J Clin Invest. 2006;116:1793-1801.

31. Kiortsis DN, Mavridis AK, Vasakos S, Nikas SN, Drosos AA. Effects of infliximab treatment on insulin resistance in patients with rheumatoid arthritis and ankylosing spondylitis. Ann Rheum Dis. 2005;64:765-766.

32. Liu G, Rondinone CM. JNK: bridging the insulin signaling and inflammatory pathway. Curr Opin Investig Drugs. 2005; 6:979-987.

33. Riachy R, Vandewalle B, Kerr CJ, et al. 1,25-dihydroxyvitamin D3 protects RINm5F and human islet cells against cytokine-induced apoptosis: implication of the antiapoptotic protein A20. Endocrinology. 2002;143:4809-4819.

34. Petersen KF, Dufour S, Befroy D, Garcia R, Shulman GI. Impaired mitochondrial activity in the insulin-resistant offspring of patients with type 2 diabetes. $N$ Engl J Med. 2004;350:664-671. 
35. Wang W, Vera L, Fischer WH, Montminy M. The CREB coactivator CRCT2 links hepatic ER stress and fasting gluconeogenesis. Nature. 2009;460:534-537.

36. McCarthy MI, Zeggini E. Genome-wide association studies in type 2 diabetes. Curr Diabetes Rep. 2009;9:164-171.

37. Krogh-Madsen R, Plomgaard P, Moller K, Mittendorfer B, Pedersen BK. Influence of TNF- $\alpha$ and IL- 6 infusions on insulin sensitivity and expression of IL-18 in humans. Am J Physiol Endocrinol Metab. 2006;291: E108-E114.

38. Pradhan AD, Manson JE, Rifai N, Buring JE, Ridker PM. C-reactive protein, interleukin 6 , and risk of developing type 2 diabetes mellitus. JAMA. 2001;286:327-334.

39. Festa A, D'Agostino R Jr, Tracy RP, Haffner SM. Elevated levels of acute-phase proteins and plasminogen activator inhibitor-1 predict the development of type 2 diabetes: the insulin resistance atherosclerosis study. Diabetes. 2002;51:1131-1137.

40. Meigs JB, Hu FB, Rifai N, Manson JE. Biomarkers of endothelial dysfunction and risk of type 2 diabetes mellitus. JAMA. 2004; 291:1978-1986.

41. Thorand B, Lowel H, Schneider A, et al. C-reactive protein as a predictor for incident diabetes mellitus among middle-aged men: results from the MONICA Augsburg cohort study, 1984-1998. Arch Intern Med. 2003;163:93-99.

42. Thorand B, Baumert J, Kolb H, et al. Sex differences in the prediction of type 2 diabetes by inflammatory markers: results from the MONICA/KORA Augsburg case-cohort study, 1984-2002. Diabetes Care. 2007;30:854-860.

43. Pradhan AD. Obesity, metabolic syndrome, and type 2 diabetes: Inflammatory basis of glucose metabolic disorders. Nutr Rev. 2007;65:S152-S156.

44. Uysal KT, Wiesbrock SM, Marino MW, Hotamisligil GS. Protection from obesityinduced insulin resistance in mice lacking TNF-alpha function. Nature. 1997;389:610-614.

45. Pickup JC. Inflammation and activate innate immunity in the pathogenesis of type 2 diabetes. Diabetes Care. 2004;27:813-823.

46. Song MJ, Kim KH, Yoon JM, Kim JB. Activation of Toll-like receptor 4 is associated with insulin resistance in adipocytes. Biochem Biophys Res Commun. 2006;346:739-745.

47. Sondergaard L. Homology between the mammalian liver and the Drosophila fat body. Trends Genet. 1993;9:193.

48. Shi H, Kokoeva MV, Inouye K, Tazmeli I, Yin H, Flier JS. TLR4 links innate immunity and fatty acid-induced insulin resistance. J Clin Invest. 2006;116:3015-3025.

49. Baumann H, Gauldie J. The acute phase response. Immunol Today. 1994;15:74-80.

50. Steel DM, Whitehead AS. The major acute phase reactants: C-reactive protein, serum amyloid $\mathrm{P}$ component and serum amyloid A protein. Immunol Today. 1994;15:81-87.

51. Gabay C, Kushner I. Acute-phase proteins and other systemic responses to inflammation. N Engl J Med. 1999;340:448-454.

52. Montecucco F, Steffens S, Mach F. Insulin resistance: A proinflammatory state mediated by lipid-induced signaling dysfunction and involved in atherosclerotic plaque instability. Mediators Inflamm. 2008;2008:767623.

53. Aguirre V, Uchida T, Yenush L, Davis R, White MF. The c-Jun NH2terminal kinase promotes insulin resistance during association with insulin receptor substrate-1 and phosphorylation of $\mathrm{Ser}^{307}$.J Biol Chem. 2000;275:9047-9054.

54. Summers SA. Ceramides in insulin resistance and lipotoxicity. Prog Lipid Res. 2006;45:42-72.

55. JeBailey L, Wanono O, Niu W, Roessler J, Rudich A, Klip A. Ceramideand oxidant-induced insulin resistance involve loss of insulin-dependent Rac-activation and actin remodeling in muscle cells. Diabetes. 2007;56:394-403.

56. Hotamisligil GS, Peraldi P, Budavari A, Ellis R, White ME, Spiegelman BM. IRS-1-mediated inhibition of insulin receptor tyrosine kinase activity in TNF- $\alpha$ - and obesity-induced insulin resistance. Science. 1996;271:665-668.
57. Yuan M, Konstantopoulos N, Lee J, et al. Reversal of obesity- and diet-induced insulin resistance with salicylates or targeted disruption of IKK $\beta$. Science. 2001;293:1673-1677.

58. Morris MF. Insulin receptor signalling and regulation. In: Pickup JC, Williams G, editors. Textbook of Diabetes. 3rd edn. Oxford, UK: Blackwell, 2003. p. 14.1-14.17.

59. Baud V, Karin M. Signal transduction by tumor necrosis factor and its relatives. Trends Cell Biol. 2001;11:372-377.

60. Hu PHZ, Couvillon AD, Kaufman RJ, Exton JH. Autocrine tumor necrosis factor alpha links endoplasmic reticulum stress to the membrane death receptor pathway through IRE1alpha-mediated NF-kappaB activation and down-regulation of TRAF2 expression. Mol Cell Biol. 2006;26:3071-3084.

61. Nguyen MT, Favelyukis S, Nguyen AK, et al. A subpopulation of macrophages infiltrates hypertrophic adipose tissue and is activated by free fatty acids via Toll-like receptors 2 and 4 and JNK-dependent pathways. J Biol Chem. 2007;282:35279-35292.

62. Zahng Y, Dall TM, Mann SE, et al. The economic costs of undiagnosed diabetes. Popul Health Manage. 2009;12:95-101.

63. Reilly MP, Rader DJ. The metabolic syndrome: more than the sum of its parts? Circulation. 2003;108:1546-1551.

64. Luscher TF, Creager MA, Beckman JA, Cosentino F. Diabetes and vascular disease: Pathophysiology, clinical consequences, and medical therapy: Part II. Circulation. 2003;108:1655-1661.

65. LeRoith D. Dyslipidemia and glucose dysregulation in overweight and obese patients. Clin Cornerstone. 2007;8:38-52.

66. Sattar N, Wannamethee SG, Forouhi NG. Novel biochemical risk factors for type 2 diabetes: pathogenic insights or prediction possibilities? Diabetologia. 2008;51:926-940.

67. Haffner SM. Insulin resistance, inflammation, and the prediabetic state. Am J Cardiol. 2003;92:18J-26J.

68. Bidwell J, Keen L, Gallagher G, et al. Cytokine gene polymorphisms in human disease on-line database. Gene Immun. 1999;1:3-19.

69. Bidwell J, Keen L, Gallagher G, et al. Cytokine gene polymorphisms in human disease on-line database, supplement 1. Gene Immun. 2001;2:61-70.

70. Haukim N, Bidwell J, Smith AJP, et al. Cytokine gene polymorphisms in human disease on-line database, supplement 2. Gene Immun. 2002;3:313-330.

71. Hollegaard MV, Bidwell LJ. Cytokine gene polymorphisms in human disease on-line database, supplement 3. Gene Immun. 2006;2006:6364301.

72. Ollier WER. Cytokine genes and disease susceptibility. Cytokine. 2004;28:174-178.

73. Wannamethee SG, Lowe GD, Rumley A, Cherry L, Whincup PH, Sattar N. Adipokines and risk of type 2 diabetes in older men. Diabetes Care. 2007;30:1200-1205.

74. Duncan BB, Schmidt MI, Pankow JS, et al. Low-grade systemic inflammation and the development of type 2 diabetes: the atherosclerosis risk in communities study. Diabetes. 2003;52:1799-1805.

75. Hu FB, Meigs JB, Li TY, Rifai N, Manson JE. Inflammatory markers and risk of developing type 2 diabetes in women. Diabetes. 2004;53:693-700.

76. Spranger J, Kroke A, Mohlig M, et al. Inflammatory cytokines and the risk to develop type 2 diabetes: results of the prospective populationbased European Prospective Investigation into Cancer and Nutrition (EPIC)-Potsdam Study. Diabetes. 2003;52:812-817.

77. Bastard JP, Maachi M, Lagathu C, et al. Recent advances in the relationship between obesity, inflammation and insulin resistance. Eur Cytokine Network. 2006;17:4-12.

78. Vassalli P. The pathophysiology of tumor necrosis factors. Аnпи Rev Immunol. 1992;10:411-452.

79. Moller DE. Potential role of TNF-a in the pathogenesis of insulin resistance and type 2 diabetes. Trends Endocrinol Metab. 2000;11:212-217.

80. Pittas AG, Lau J, Hu FB, Dawson-Hughes B. Review: The role of vitamin $\mathrm{D}$ and calcium in type 2 diabetes. A systematic review and meta-analysis. J Clin Endocrinol Metabol. 2007;92:2017-2029. 
81. Kubaszek SA, Pihlajamaki J, Komarovski V, et al. Finnish diabetes prevention study: promoter polymorphisms of the TNF- $\alpha$ (G-308A) and IL-6 (C-174G) genes predict the conversion from impaired glucose tolerance to type 2 diabetes: the Finnish diabetes prevention study. Diabetes. 2003;52:1872-1876.

82. Hoffstedt J, Eriksson PHL, Rossner S, Ryden PAM. Excessive fat accumulation is associated with the TNF $\alpha-308 \mathrm{G} / \mathrm{A}$ promoter polymorphism in women but not in men. Diabetologia. 2000;43:117-120.

83. Susa S, Daimon M, Sakabe J, et al. A functional polymorphism of the TNF-alpha gene that is associated with type 2 DM. Biochem Biophys Res Commun. 2008;369:943-947.

84. Rasmussen SK, Urhammer SA, Jensen JN, Hansen T, BorchJohnsen K, Pedersen O. The -238 and $-308 \mathrm{G}>\mathrm{A}$ polymorphisms of the tumor necrosis factor a gene promoter are not associated with features of the insulin resistance syndrome or altered birth weight in Danish Caucasians. J Clin Endocrinol Metab. 2000;85:1731-1734.

85. Zeggini E, Groves CJ, Parkinson JR, et al. Large-scale studies of the association between variation at the TNF/LTA locus and susceptibility to type 2 diabetes. Diabetologia. 2005;48:2013-2017.

86. Kroeger KM, Carville KS, Abraham LJ. The -308 tumor necrosis factor- $\alpha$ promoter polymorphism effects transcription. Mol Immunol. 1997;34:391-399.

87. Fong CL, Siddiqui AH, Mark DF. Identification and characterization of a novel repressor site in the human tumor necrosis factor alpha gene. Nucleic Acids Res. 1994;22:1108-1114.

88. Fried SK, Bunkin DA, Greenberg AS. Omental and subcutaneous adipose tissues of obese subjects release interleukin-6: depot difference and regulation by glucocorticoid. J Clin Endocrinol Metab. 1998;83:847-850.

89. Fain JN, Madan AK, Hiler ML, Cheema P, Bahouth SW. Comparison of the release of adipokines by adipose tissue, adipose tissue matrix, and adipocytes from visceral and subcutaneous abdominal adipose tissues of obese humans. Endocrinology. 2004;145:2273-2282.

90. Mohamed-Ali V, Goodrick S, Rawesh A, et al. Subcutaneous adipose tissue releases interleukin-6, but not tumor necrosis factor- $\alpha$, in vivo. J Clin Endocrinol Metab. 1997;82:4196-4200.

91. Orban Z, Remaley AT, Sampson M, Trajanoski Z, Chrousos GP. The differential effect of food intake and beta-adrenergic stimulation on adipose-derived hormones and cytokines in man. J Clin Endocrinol Metab. 1999;84:2126-2133.

92. Sandler S, Bendtzen K, Eizirik DL, et al. Interleukin-6 affects insulin secretion and glucose metabolism of rat pancreatic islets in vitro. Endocrinology. 1990;126:1288-1294.

93. Bastard JP, Maachi M, Van Nhieu JT, et al. Adipose tissue IL-6 content correlates with resistance to insulin activation of glucose uptake both in vivo and in vitro. J Clin Endocrinol Metab. 2002;87:2084-2089.

94. Maachi M, Pieroni L, Bruckert E, et al. Systemic low-grade inflammation is related to both circulating and adipose tissue $\mathrm{TNF} \alpha$, leptin and IL-6 levels in obese women. Int J Obes Relat Metab Disord. 2004;28:993-997.

95. Bastard JP, Jardel C, Bruckert E, et al. Elevated levels of interleukin -6 are reduced in serum and subcutaneous adipose tissue of obese women after weight loss. J Clin Endocrinol Metab. 2000; $85: 3338-3342$.

96. Nonogaki K, Fuller GM, Fuentes NL, et al. Interleukin-6 stimulates hepatic triglyceride secretion in rats. Endocrinology. 1995;136: 2143-2149.

97. Yudkin JS, Kumari M, Humphries SE, Mohamed-Ali V. Inflammation, obesity, stress and coronary heart disease: is interleukin-6 the link? Atherosclerosis. 2000;148:209-214.

98. Grimble RF. Inflammatory status and insulin resistance. Curr Opin Clin Nutr Metab Care. 2002;5:551-559.

99. Ihle JN, Witthuhn BA, Quelle FW, Yamamoto K, Silvennoinen O. Signaling through the hematopoietic cytokine receptors. Annu Rev Immunol. 1995;13:369-398.

100. Kristiansen OP, Mandrup-Poulsen T. Interleukin-6 and diabetes: the good, the bad, or the indifferent? Diabetes. 2005;54(Suppl 2): S114-S124.
101. Hirosumi J, Tuncman G, Chang L, et al. A central role for JNK in obesity and insulin resistance. Nature. 2002;420:333-336.

102. Mooney RA, Senn J, Cameron S, et al. Suppressors of cytokine signaling-1 and -6 associate with and inhibit the insulin receptor. A potential mechanism for cytokine-mediated insulin resistance. $J$ Biol Chem. 2001;276:25889-25893.

103. Lagathu C, Bastard JP, Auclair M, Maachi M, Capeau J, Caron M. Chronic interleukin-6 (IL-6) treatment increased IL-6 secretion and induced insulin resistance in adipocyte: prevention by rosiglitazone. Biochem Biophys Res Commun. 2003;311:372-379.

104. Rieusset J, Bouzakri K, Chevillotte E, et al. Suppressor of cytokine signaling 3 expression and insulin resistance in skeletal muscle of obese and type 2 diabetic patients. Diabetes. 2004;53:2232-2241.

105. Hundal RS, Peterson KF, Mayerson AB, et al. Mechanism by which high-dose aspirin improves glucose metabolism in type 2 diabetes. J Clin Invest. 2002;109:1321-1326.

106. Huth C, Heid IM, Vollmert C, et al. IL6 gene promoter polymorphisms and type 2 diabetes: joint analysis of individual participants' data from 21 studies. Diabetes. 2006;55:2915-2921.

107. Gewurz H, Zhang XH, Lint TF. Structure and function of the pentraxins. Curr Opin Immunol. 1995;7:54-64.

108. Pearson TA, Mensah GA, Alexander RW, et al. Markers of inflammation and cardiovascular disease: application to clinical and public health practice: A statement for healthcare professionals from the Centers for Disease Control and Prevention and the American Heart Association. Circulation. 2003;107:499-511.

109. Dehghan A, Kardys I, de Maat MP, et al. Genetic variation, C-reactive protein levels, and incidence of diabetes. Diabetes. 2007;56:872-878.

110. Doi Y, Kiyohara Y, Kubo M, et al. Elevated C-reactive protein is a predictor of the development of diabetes in a general Japanese population: the Hisayama Study. Diabetes Care. 2005;28:2497-2500.

111. Laaksonen DE, Niskanen L, Nyyssonen K, et al. C-reactive protein and the development of the metabolic syndrome and diabetes in middleaged men. Diabetologia. 2004;47:1403-1410.

112. Nakanishi S, Yamane K, Kamei N, Okubo M, Kohno N. Elevated $\mathrm{C}$-reactive protein is a risk factor for the development of type 2 diabetes in Japanese Americans. Diabetes Care. 2003;26:2754-2757.

113. Freeman DJ, Norrie J, Caslake MJ, et al. C-reactive protein is an independent predictor of risk for the development of diabetes in the West of Scotland Coronary Prevention Study. Diabetes. 2002;51:1596-1600.

114. Barzilay JI, Abraham L, Heckbert SR, et al. The relation of markers of inflammation to the development of glucose disorders in the elderly: the Cardiovascular Health Study. Diabetes. 2001;50:2384-2389.

115. Krakoff J, Funahashi T, Stehouwer CD, et al. Inflammatory markers, adiponectin, and risk of type 2 diabetes in the Pima Indian. Diabetes Care. 2003;26:1745-1751.

116. Lee CC, Adler AI, Sandhu MS, et al. Association of C-reactive protein with type 2 diabetes: prospective analysis and meta-analysis Diabetologia. 2009;52:1040-1047

117. Anan F, Takahashi N, Nakagawa M, Ooie T, Saikawa T, Yoshimatsu H. High-sensitivity C-reactive protein is associated with insulin resistance and cardiovascular autonomic dysfunction in type 2 diabetic patients. Metabolism. 2005;54:552-558.

118. Pfutzner A, Standl E, Strotmann HJ, et al. Association of high-sensitive C-reactive protein with advanced stage beta-cell dysfunction and insulin resistance in patients with type 2 diabetes mellitus. Clin Chem Lab Med. 2006;44:556-560.

119. Nabata A, Kuroki M, Ueba H, et al. C-reactive protein induces endothelial cell apoptosis and matrix metalloproteinase-9 production in human mononuclear cells: Implications for the destabilization of atherosclerotic plaque. Atherosclerosis. 2008;196:129-135.

120. Hage FG, Szalai AJ. C-reactive protein gene polymorphisms, $\mathrm{C}$-reactive protein blood levels, and cardiovascular disease risk. $J \mathrm{Am}$ Coll Cardiol. 2007;50:1115-1122.

121. Obisesan TO, Leeuwenburgh C, Ferrell RE, et al. C-reactive protein genotype affects exercise training-induced changes in insulin sensitivity. Metabolism. 2006;55:453-460. 
122. Wolford JK, Gruber JD, Ossowski VM, et al. A C-reactive protein promoter polymorphism is associated with type 2 diabetes mellitus in Pima Indians. Mol Genet Metab. 2003;78:136-144.

123. Zee RY, Germer S, Thomas A, et al. C-reactive protein gene variation and type 2 diabetes mellitus: a case-control study. Atherosclerosis. 2008;197:931-936.

124. Lange LA, Burdon K, Langefeld CD, et al. Heritability and expression of C-reactive protein in type 2 diabetes in the Diabetes Heart Study. Ann Hum Genet. 2006;70:717-725.

125. Grammer TB, Marz W, Renenr W, Bohm BO, Hoffmann MM. $\mathrm{C}$-reactive protein genotypes associated with circulating $\mathrm{C}$-reactive protein but not with angiographic coronary artery disease: the LURIC study. Eur Heart J. 2009;30:170-182.

126. Kushner I, Jiang SL, Zhang D, Lozanski G, Samols D. Do posttranscriptional mechanisms participate in induction of C-reactive protein and serum amyloid A by IL-6 and IL-1? Ann NY Acad Sci. 1995;762:102-107.

127. Vickers MA, Green FR, Terry C, et al. Genotype at a promoter polymorphism of the interleukin-6 gene is associated with baseline levels of plasma C-reactive protein. Cardiovasc Res. 2002;53:1029-1034.

128. Libra M, Signorelli SS, Bevelacqua Y, et al. Analysis of G(-174)C IL-6 polymorphism and plasma concentrations of inflammatory markers in patients with type 2 diabetes and peripheral arterial disease. J Clin Pathol. 2006;59:211-215.

129. Paik JK, Kim OY, Koh SJ, et al. Additive effect of interleukin-6 and C-reactive protein (CRP) single nucleotide polymorphism on serum CRP concentration and other cardiovascular risk factors. Clin Chim Acta. 2007;380:68-74.

130. Rendell M. The role of sulphonylureas in the management of type 2 diabetes mellitus. Drugs. 2004;64:1339-1358.

131. Kirpichnikov D, McFarlane SI, Sowers JR. Metformin: An update. Ann Intern Med. 2002;137:25-33.

132. Krentz AJ, Bailey CJ. Oral antidiabetic agents: Current role in type 2 diabetes mellitus. Drugs. 2005;65:385-411.

133. Delerive P, Fruchart JC, Staels B. Peroxisome proliferator-activated receptors in inflammation control. J Endocrinol. 2001;169:453-459.

134. Fukuzawa M, Satoh J, Qiang X, et al. Inhibition of tumor necrosis factor-alpha with anti-diabetic agents. Diabetes Res Clin Pract. 1999;43:147-154.

135. Shoelson SE, Lee M, Yuan M. Inflammation and the IKK beta/I kappa B/NF-kappa B axis in obesity- and diet-induced insulin resistance. Int J Obes Related Metab Disord. 2003;27(Suppl 3):S49-S52.

136. Robertson RP. Prostaglandins as modulators of pancreatic islet function. Diabetes. 1979;28:942-948.

137. Robertson RP. Arachidonic acid metabolism, the endocrine pancreas, and diabetes mellitus. Pharmacol Ther. 1984;24:91-106.

138. Maggini S, Wintergerst ES, Beveridge S, Hornig DH. Selected vitamins and trace elements support immune function by strengthening epithelial barriers and cellular and humoral immune responses. $\mathrm{Br} J$ Nutr. 2007;98(Suppl 1):S29-S35.

139. Pittas AG, Dawson-Hughes B, Li T, et al. Vitamin D and calcium intake in relation to type 2 diabetes in women. Diabetes Care. 2006;29:650-656.

140. Haddad PS, Azar GA, Groom S, Boivin M. Natural health products, modulation of immune function and prevention of chronic diseases. Evid Based Complement Alternat Med. 2005;2:513-520.

141. Holick MF. Vitamin D: a D-Lightful health perspective. Nutr Rev. 2008;66(Suppl 2):S182-S194.
142. Holick MF. Diabetes and the vitamin D connection. Curr Diabetes Rep. 2008;8:393-398.

143. Fu L, Yun F, Oczak M, Wong BYL, Veith R, Cole DEC. Common genetic variants of the vitamin $\mathrm{D}$ binding protein (DBP) predict differences in response of serum 25-hydroxyvitamin D [25(OH)D] to vitamin D supplementation. Clin Biochem. 2009;42:1174-1177.

144. Hirai M, Suzuki S, Hinokio Y, et al. Variation in vitamin D-binding protein (group-specific component protein) are associated with fasting plasma insulin levels in Japanese with normal glucose tolerance. J Clin Endocrinol Metab. 2000;85:1951-1953.

145. Bair LJ, Dobberfuhl AM, Pratley RE, Hanson RL, Bogardus C. Variation in the vitamin D-binding protein (Gc locus) are associated with oral glucose tolerance in nondiabetic Pima Indians. J Clin Endocrinol Metab. 1998;83:2993-2996.

146. Szathmary EJ. The effect of Gc genotype on fasting insulin level in Dogrib Indians. Hum Genet. 1987;75:368-372.

147. Hayes CE, Nashold FE, Spach KM, Pedersen LB. The immunological functions of the vitamin D endocrine system. Cell Mol Biol. 2003;49:277-300.

148. Griffin MD, Xing N, Kumar R. Vitamin D and its analogs as regulators of immune activities and antigen presentation. Annu Rev Nutr. 2003;23:117-145.

149. Cantorna MT, Zhu Y, Froicu M, Wittke A. Vitamin D status, 1,25-dihydroxy-vitamin D3, and the immune system. Am J Clin Nutr. 2004;80:1717S-1720S.

150. Veldman CM, Cantorna MT, DeLuca HF. Expression of 1,25dihydroxyvitamin D3 receptor in the immune system. Arch Biochem Biophys. 2000;374:334-338.

151. DeLuca HF, Cantorna MT. Vitamin D: its role and uses in immunology. FASEB J. 2001;15:2579-2585.

152. van Etten E, Mathieu C. Immunoregulation by 1,25-dihydroxyvitamin D3: basic concepts. J Steroid Biochem Mol Biol. 2005;97:93-101.

153. Han SN, Adolfsson O, Lee CK, Prolla TA, Ordovas J, Meydani SN. Vitamin E and gene expression in immune cells. Ann N Y Acad Sci. 2004;1031:96-101.

154. Adolfsson O, Huber BT, Meydani SN. Vitamin E-enhanced IL-2 production in old mice: naive but not memory $\mathrm{T}$ cells show increased cell division cycling and IL-2 -producing capacity. J Immunol. 2001;167:3809-3817.

155. Singh U, Jialal I. Anti-inflammatory effects of $\alpha$-tocopherol. Ann NY Acad Sci. 2004;1031:195-203.

156. Devaraj JS, Jialal I. Alpha-tocopherol decreases interleukin-1 beta release from activated human monocytes by inhibition of 5-lipoxygenase. Arterioscler Thromb Vasc Biol. 1999;19:1125-1133.

157. Scott JA, King GL. Oxidative stress and antioxidant treatment in diabetes. Ann NY Acad Sci. 2004;1031:204-213.

158. Thomas SR, Stocker R. Molecular action of vitamin E in lipoprotein oxidation: Implications for athrosclerosis. Free Radic Biol Med. 2000;28:1795-1805.

159. Ristow M, Zarse K, Oberbach A, et al. Antioxidants prevent healthpromoting effects of physical exercise in humans. Proc Natl Acad Sci US A. 2009;106:8665-8670.

160. Buijsee B, Feskens EJM, Kwape L, Kok FJ, Kormhout D. Both alphaand beta-carotene, but not tocopherols and vitamin $\mathrm{C}$, are inversely related to 15 -year cardiovascular mortality in Dutch elderly men. J Nutr. 2008;138:344-350.

Diabetes, Metabolic Syndrome and Obesity: Targets and Therapy

\section{Publish your work in this journal}

Diabetes, Metabolic Syndrome and Obesity: Targets and Therapy is an international, peer-reviewed open-access journal committed to the rapid publication of the latest laboratory and clinical findings in the fields of diabetes, metabolic syndrome and obesity research. Original research, review, case reports, hypothesis formation, expert

\section{Dovepress}

opinion and commentaries are all considered for publication. The manuscript management system is completely online and includes a very quick and fair peer-review system, which is all easy to use. Visit http://www.dovepress.com/testimonials.php to read real quotes from published authors. 